\title{
Association of Neurofibromatosis Type 1 with Primary Hyperparathyroidism: Report of a Case
}

Dr E. Austin, Dr J Henderson, Dr D. Howe, Dr A. Bates

Heart of England Foundation Trust, Birmingham, UK

\section{Introduction}

- Neurofibromatosis Type 1 (NF1) is an autosomal dominant inherited disorder, which increases the risk of developing both benign and malignant tumours ${ }^{1}$.

- A Swedish study conducted by Zöller et al in 1997 , suggested that up to $25 \%$ of these tumours are neuroendocrine in origin, of which phaeochromocytomas were the commonest with a prevalence of $0.1-6 \%^{2}$. Of the 70 patients with NF1 included in this study, 1 had a parathyroid adenoma².

- The association between NF1 and primary hyperparathyroidism is described in the literature but clinically rare.

\section{Case}

This case is a 42-year-old gentleman known to have NF1, with disease manifestations including multiple cutaneous neurofibromas and café au lait spots.

He was referred due to hypercalcaemia after presenting to his General Practitioner with abdominal discomfort. On examination, his pulse was regular at 82 beats per minute, and his blood pressure was $148 / 78 \mathrm{mmHg}$. The diagnosis of primary hyperparathyroidism was biochemically confirmed, with a corrected calcium of 2.82 $\mathrm{mmol} / \mathrm{L}$ (normal range 2.2-2.6 mmol/L) and PTH $110 \mathrm{pg} / \mathrm{ml}$ (normal range $15-65 \mathrm{pg} / \mathrm{ml}$ ).

There was no clinical suggestion of phaeochromocytoma and 24-hour urinary metanephrines were normal.

Imaging studies shown in figure 1 and 2 demonstrated a possible lesion behind the middle of the left lobe of the thyroid, which was most likely an adenoma.

The patient underwent a parathyroidectomy, and the histology as seen in figure 3 was confirmed as parathyroid hyperplasia.

The hypercalcaemia resolved post-operatively, with a corrected calcium of $2.35 \mathrm{mmol} / \mathrm{L}$.
Figure 1 (below): USS parathyroid - small area of fullness behind the lower third of the left lobe

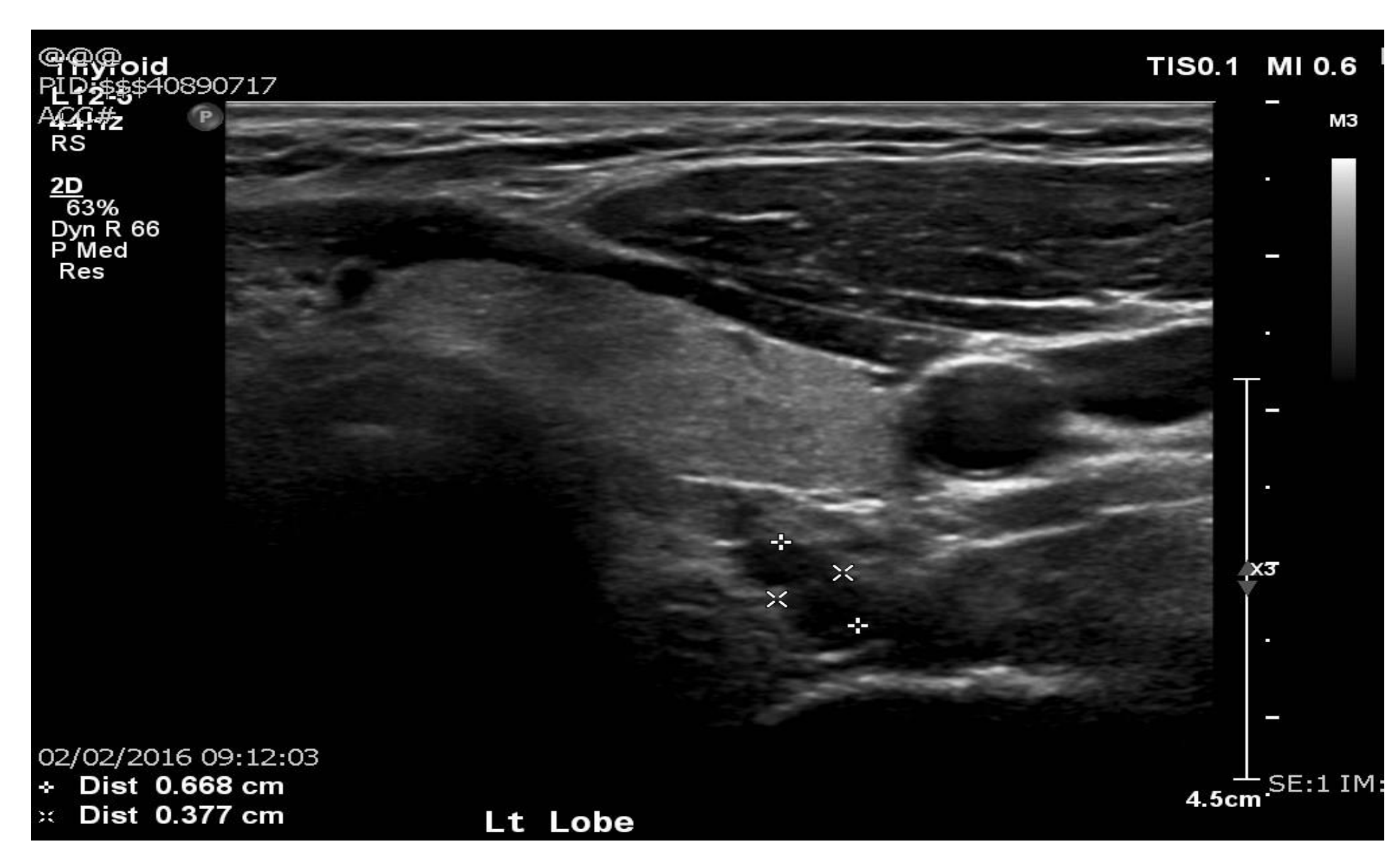

Figure 3 (below): histology - parathyroid hyperplasia

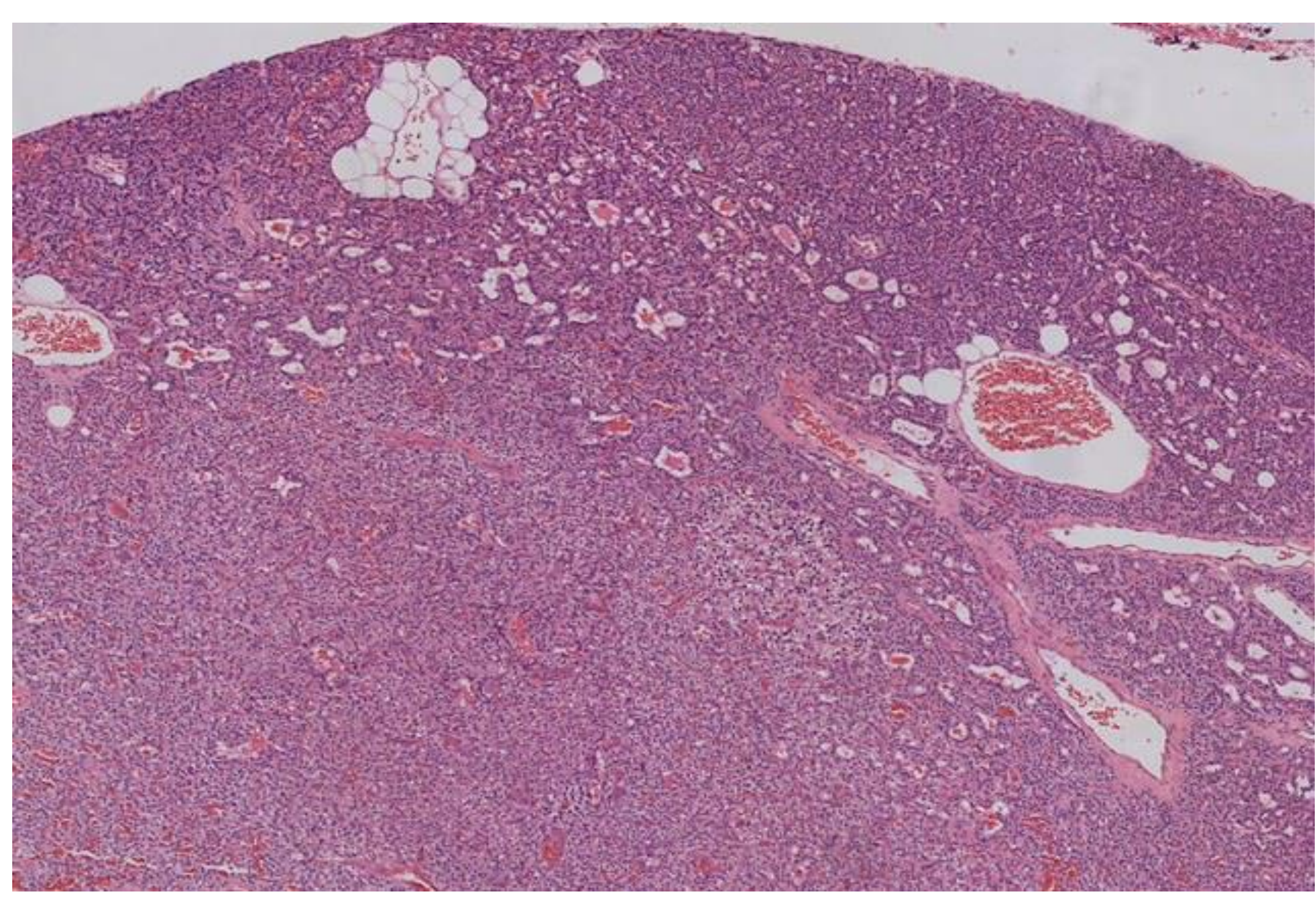

Figure 2 (below): CT neck - lesion behind the middle of the left lobe of the thyroid
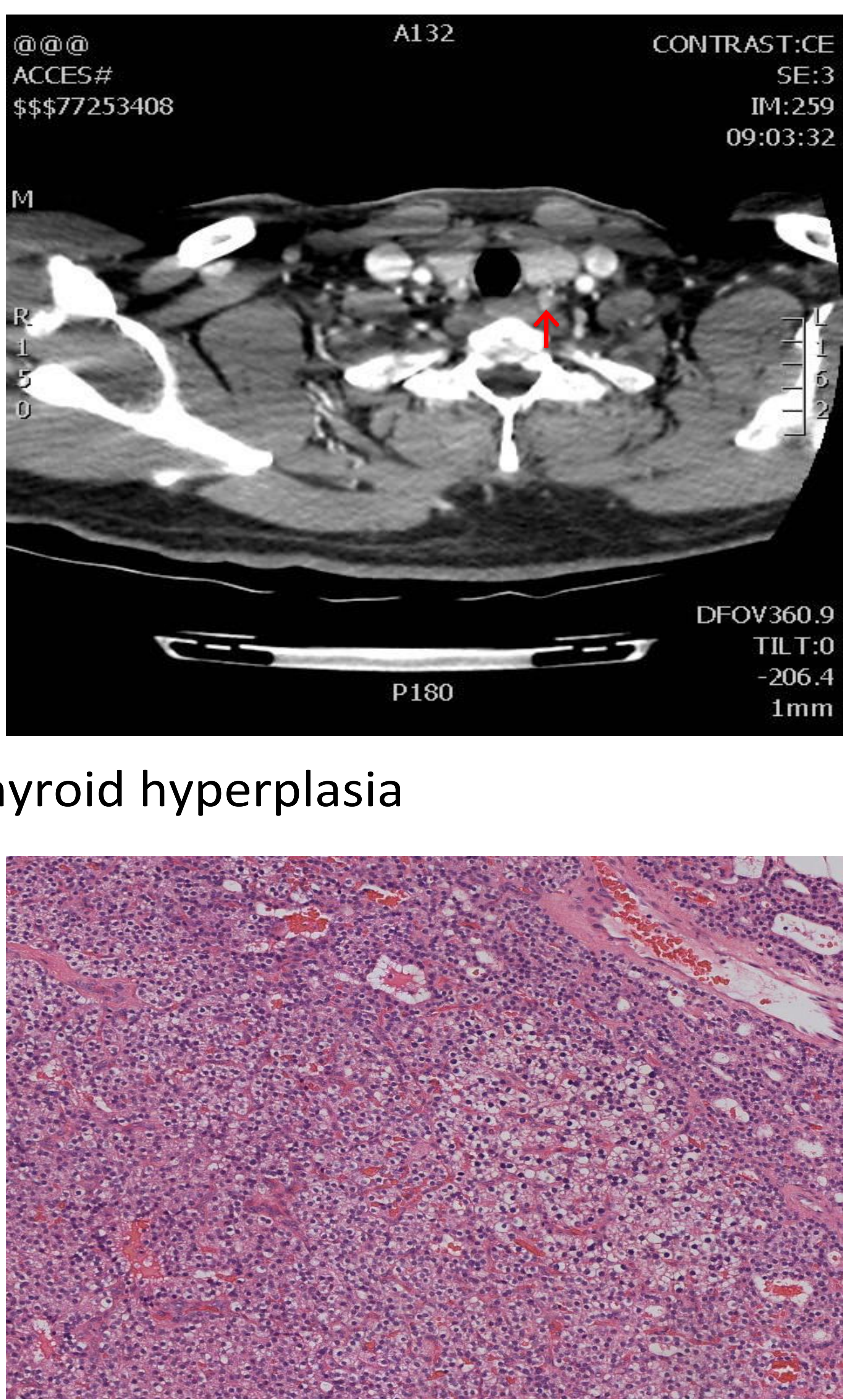

\section{Discussion and Recommendations}

- A literature review has identified 17 other cases of hyperparathyroidism associated with Neurofibromatosis to date. The vast majority of these cases were due to a parathyroid adenoma in patients of a mean age of 45 years.

- Several hypotheses have been suggested to explain the link between these conditions, one of which is that NF1 in association with primary hyperparathyroidism may be a variant of MEN2 $2^{2,3}$.

- Given this association, and considering that patients with NF1 present at a relatively young age, it is appropriate to screen these patients for primary hyperparathyroidism, as it is likely that the majority would be candidates for parathyroidectomy ${ }^{4,5}$.

\section{References}

1. A Abbas. Disease caused by immune responses: hypersensitivity and autoimmunity. In: Abbas A, Lichtman AH, editors. Cellular and molecular immunology. $5^{\text {th }}$ edition. Philadelphia: Saunders; 2005. p. 411-31

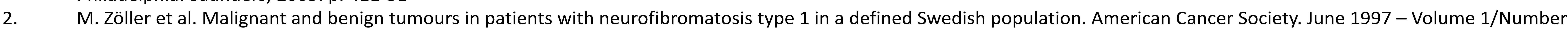
11

H. Kodama et al. Water-clear cell parathyroid adenoma causing primary hyperparathyroidism in a patient with neurofibromatosis type 1: report of a case. Surgery Today (2007) 37: 884-887

K. Behera et al. Neurofibromatosis type 1, phaeochromocytoma with primary hyperparathyroidism: A rare association. Indian Journal of Endocrinology and Metabolism. Mar-Apr 2013. Volume 17, Issue 2, p. 349-351

D. Daly et al. Neurofibromatosis and hyperparathyroidism - A new syndrome? C.M.A Journal. August 1970. Volume 103. p258-259 